\title{
GROMOS-C, a novel ground-based microwave radiometer for ozone measurement campaigns
}

\author{
S. Fernandez, A. Murk, and N. Kämpfer \\ Institute of Applied Physics, University of Bern, Bern, Switzerland \\ Correspondence to: S. Fernandez (susana.fernandez@iap.unibe.ch)
}

Received: 26 November 2014 - Published in Atmos. Meas. Tech. Discuss.: 19 March 2015

Revised: 05 June 2015 - Accepted: 05 June 2015 - Published: 02 July 2015

\begin{abstract}
Stratospheric ozone is of major interest as it absorbs most harmful UV radiation from the sun, allowing life on Earth. Ground-based microwave remote sensing is the only method that allows for the measurement of ozone profiles up to the mesopause, over 24 hours and under different weather conditions with high time resolution.

In this paper a novel ground-based microwave radiometer is presented. It is called GROMOS-C (GRound based Ozone MOnitoring System for Campaigns), and it has been designed to measure the vertical profile of ozone distribution in the middle atmosphere by observing ozone emission spectra at a frequency of $110.836 \mathrm{GHz}$. The instrument is designed in a compact way which makes it transportable and suitable for outdoor use in campaigns, an advantageous feature that is lacking in present day ozone radiometers. It is operated through remote control.

GROMOS-C is a total power radiometer which uses a pre-amplified heterodyne receiver, and a digital fast Fourier transform spectrometer for the spectral analysis. Among its main new features, the incorporation of different calibration loads stands out; this includes a noise diode and a new type of blackbody target specifically designed for this instrument, based on Peltier elements. The calibration scheme does not depend on the use of liquid nitrogen; therefore GROMOS-C can be operated at remote places with no maintenance requirements. In addition, the instrument can be switched in frequency to observe the $\mathrm{CO}$ line at $115 \mathrm{GHz}$.

A description of the main characteristics of GROMOS-C is included in this paper, as well as the results of a first campaign at the High Altitude Research Station at Jungfraujoch (HFSJ), Switzerland. The validation is performed by comparison of the retrieved profiles against equivalent profiles from MLS (Microwave Limb Sounding) satellite data, ECMWF
\end{abstract}

(European Centre for Medium-Range Weather Forecast) model data, as well as our nearby NDACC (Network for the Detection of Atmospheric Composition Change) ozone radiometer measuring at Bern.

\section{Introduction}

Stratospheric ozone protects and allows life on Earth since it filters most of the harmful ultraviolet radiation emitted by the sun. It also controls the thermal state of the middle atmosphere by heating the stratosphere as a consequence of this absorption of UV radiation. Ozone is therefore an atmospheric molecule of major interest since variations in its concentration can significantly alter the radiative balance and consequently influence climate through the resulting temperature and circulation changes (Dall'Amico et al., 2010). On the other hand changes in the stratospheric temperature due to an increase of greenhouse gases affect the chemistry of ozone and hence its abundance. Additionally climate models predict an acceleration of the Brewer-Dobson circulation in response to increasing greenhouse gases that would also have an impact on the ozone distribution (Butchart et al., 2006).

The ozone layer depletion due to anthropogenic chemicals was an important research topic during the 1980-1990s, with a special attention to the ozone hole over the Antarctic (Farman et al., 1985). Since the Montreal protocol in 1987 and the banning of emissions of chlorofluorocarbons a moderate recovery of the ozone layer has been observed (Steinbrecht et al., 2009), yet models predict a faster recovery should happen. In addition, unprecedented chemical ozone destruction over the Arctic comparable to that in the Antarctic has been observed in 2011 for the first time (Manney et al., 2011); this 
brings the interest of the atmospheric scientific community back to the study of the spatiotemporal fluctuations of this molecule.

Ozone can further be used as a tracer to study atmospheric dynamic processes, as it is shown for example in Flury et al. (2009), where a decrease of ozone is observed during a sudden stratospheric warming.

Different techniques have been developed to measure ozone profiles. In situ measurements can be performed using radiosondes, balloons and airplanes. The main drawback of these direct methods is the flight altitude limitations which can hardly reach the upper stratosphere. Remote sensing techniques allow to retrieve ozone profiles in a much larger altitude range. Satellite-borne radiometers provide a good vertical resolution; however they only pass a maximum of 2 times a day by the same position and hence the temporal resolution is insufficient for dynamic studies (Hocke et al., 2007). Ground-based instruments are optimal when the requirement is a high temporal resolution at a fixed position. Lidars have a very good vertical resolution but suffer from the drawback of measuring only during nighttime and under clear sky conditions (Godin-Beekmann and Nair, 2012). Ground-based microwave radiometry is therefore the only method that allows for the measurement of ozone profiles up to the mesopause, during $24 \mathrm{~h}$ and under different weather conditions, with high temporal resolution.

Microwave radiometry is a passive technique based on the detection and analysis of radiation emitted by molecules undergoing rotational transitions in the millimetre wave range. In this frequency range, ozone presents two main emission lines which are typically used for radiometry: 110.8 and $142.2 \mathrm{GHz}$. The transition strength of these lines leads to fairly strong line emission throughout the stratosphere and mesosphere (Fig. 1).

The first observation of ozone profiles with a passive millimetre wave radiometer was made in 1976 (Penfield et al., 1976). Nowadays there are a few ground-based ozone radiometers sites in the world. Most of them are gathered under the international organization NDACC (Network for the Detection of Atmospheric Composition Change) with permanent instruments located at observation stations in $\mathrm{Ny}$ Alesund (Spitsbergen) (Palm et al., 2010), Bern (Switzerland) (Studer et al., 2013), Payerne (Switzerland) (Maillard Barras et al., 2009), Mauna Loa (Hawaii), Lauder (New Zealand) (Boyd et al., 2007) and Rikubetsu (Japan) (Nagahama et al., 2007). In addition, other ozone radiometers are located in Thule (Greenland), Seoul (Korea), Kiruna (Sweden), Moscow (Russia) and in Antarctica. Still there are many world areas not covered by this network of radiometers where high-quality continuous ozone time series would be needed, what justifies the necessity of building a compact transportable instrument for measurement campaigns.

The Institute of Applied Physics (IAP) of the University of Bern has a long experience in microwave remote sensing of the atmosphere (Kaempfer, 1995). The first ozone radiometer

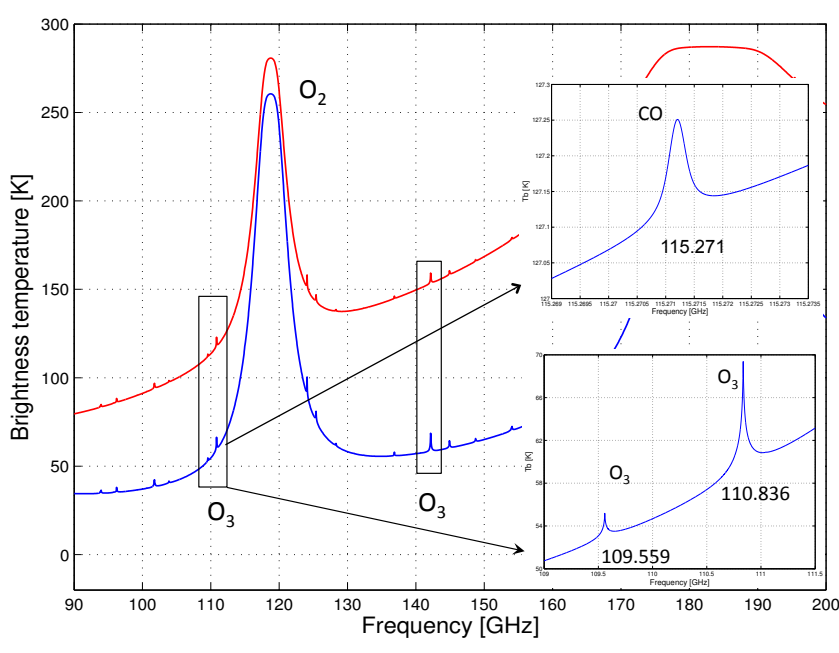

Figure 1. The emission spectrum of a midlatitude standard atmosphere in winter (blue) and summer (red), for an elevation angle of $45^{\circ}$ and an altitude of $500 \mathrm{~m}$, simulated with ARTS. The $\mathrm{O}_{3}$ and $\mathrm{CO}$ lines are highlighted.

built at the institute was in 1984 (Lobsiger et al., 1984). Diurnal variations of mesospheric ozone detected by microwave radiometry at IAP were reported as early as 1989 (Zommerfelds et al., 1989). Since then several instruments have been developed and operated in the frame of NDACC for ozone and water vapour. In addition, we have recently started the development of a new generation of radiometers to be used under campaign conditions. GROMOS-C is the third transportable instrument built by the IAP, after the water vapour radiometer MIAWARA-C (Straub et al., 2010) and the wind radiometer WIRA (Rüfenacht et al., 2012).

The instrument presented in this paper measures the spectra of the ozone emission line at $110.836 \mathrm{GHz}$. As it has been mentioned above the motivation behind the construction of this new instrument is to have an ozone profiler that can be easily transported and suited for measurement campaigns all over the world. It is a total power radiometer that covers an altitude range between 23 and $70 \mathrm{~km}$, needs no maintenance, is operated outdoors and remotely controlled.

In the first measurement campaign, GROMOS-C was located at the Sphinx station at Jungfraujoch (HFSJ, Switzerland), at an altitude of $3580 \mathrm{~m}$, where the very dry troposphere ensures low absorption of the middle-atmospheric emissions. Ozone spectra were recorded from January to March 2014. Vertical profiles have been retrieved from this data and validated against equivalent profiles from satellite and model data, as well as our ozone radiometer measuring at Bern in the frame of NDACC (GROMOS), located $60 \mathrm{~km}$ north-west.

The present paper is organized as follows: Sect. 2 provides a detailed description of GROMOS-C, focusing on the optics design and the calibration scheme. Section 3 presents results of measured spectra and explains the data analysis performed 


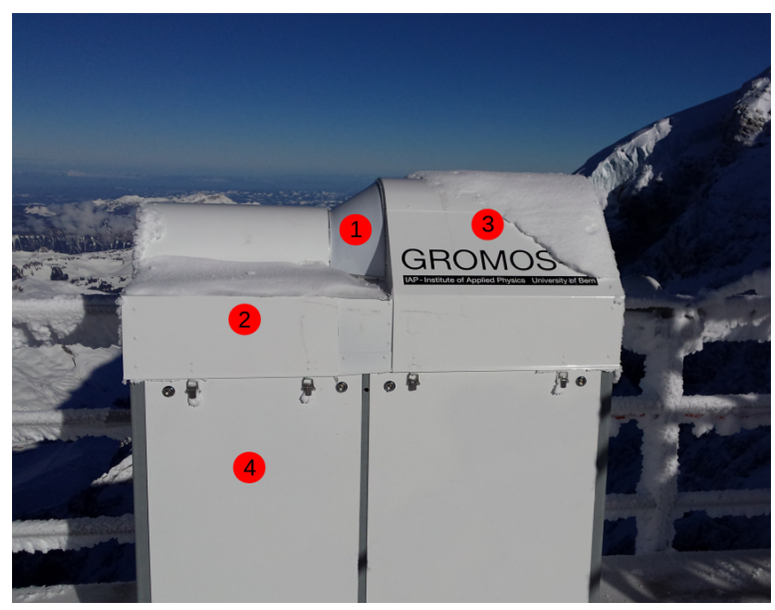

Figure 2. GROMOS-C at the terrace of Sphinx during the Jungfraujoch campaign (1: Teflon window, 2: Microwave receiver, 3: Calibration targets, 4: Computer and spectrometer).

and the retrieval implementation with Qpack and ARTS software. The measurement campaign at Jungfraujoch is presented in Sect. 4, including the validation of the retrieved profiles. Finally, Sect. 5 concludes this paper.

\section{Instrument measurement principle}

GROMOS-C measures the spectral intensity of the pressure broadened ozone emission line at $110.836 \mathrm{GHz}$ (Fig. 1). This frequency was chosen over the stronger line at $142.175 \mathrm{GHz}$ because it is less affected by water vapour fluctuations, and the observation of a lower frequency allows for the retrieval of higher altitudes as Doppler broadening is smaller for lower frequencies. But also because nearby there is a second ozone emission line, at $109.559 \mathrm{GHz}$ (Fig. 1), which we intend to use for verifications. The local oscillator of GROMOS$\mathrm{C}$ can be tuned to select between the two lines. Its frequency can also be shifted to detect the $\mathrm{CO}$ emission line at $115.271 \mathrm{GHz}$.

Given a measured line, the information of the vertical distribution of the molecule is retrieved from the pressure dependence of the line width. No information about the vertical distribution can be retrieved above the altitude where Doppler broadening starts to govern the total line width. The upper limit for the retrieval of ozone from the line at $110.836 \mathrm{GHz}$ is about $70 \mathrm{~km}$. The lower boundary is given by the bandwidth of the spectrometer and the retrieval settings.

The radiative transfer theory describes the intensity of radiation propagating in a general medium that absorbs, emits and scatters radiation. For microwave radiation we can neglect scattering because of the relatively long wavelength. Considering Planck's radiation law in the Rayleigh-Jeans ap-
Table 1. Summary of GROMOS-C main characteristics. FFTS stands for fast Fourier transform spectrometer.

\begin{tabular}{ll}
\hline Optical system & $\begin{array}{l}\text { Ultra-Gaussian feed-horn }+ \\
\text { system of elliptic and flat mirrors }\end{array}$ \\
Beam width & $5^{\circ}$ (full width at half maximum) \\
Receiver type & Preamplified heterodyne receiver \\
Operation mode & Single side band \\
Receiver noise temperature & $1080 \mathrm{~K}$ \\
Radio frequency range & $109-118 \mathrm{GHz}$ \\
Back end & FFTS, $1 \mathrm{GHz}$ bandwidth \\
Spectral resolution & $30.5 \mathrm{kHz}$ \\
Calibration & hot $/$ cold + noise diode + tipping curve \\
Altitude range & $23-70 \mathrm{~km}$ \\
\hline
\end{tabular}

proximation for low frequencies:

$B=\frac{2 \cdot k \cdot T}{\lambda^{2}}$,

where $B$ is the spectral radiance emitted by a blackbody, $k$ is the Boltzmann constant, $\lambda$ the wavelength and $T$ the temperature of the blackbody. We define for a non-blackbody an equivalent temperature of radiation called brightness temperature, $T_{\mathrm{b}}$, and use it as a measure of intensity of radiation. In this approximation the radiative transfer equation for microwave can be expressed as follows:

$T_{\mathrm{b}}=T_{\mathrm{b} 0} \cdot e^{-\tau_{0}}+\int_{0}^{\tau_{0}} T \cdot e^{-\tau} \mathrm{d} \tau$,

where $T_{\mathrm{b}}$ is the brightness temperature measured at the earth surface, $T_{\mathrm{b} 0}$ the microwave background temperature, $T$ the temperature profile along a path $s$ and $\tau$ the optical thickness, which is defined as the integral of the absorption coefficient $\alpha$ through the path $s$ :

$\tau=\int_{0}^{s} \alpha(s) \mathrm{d} s$.

The task of a microwave radiometer is to measure $T_{\mathrm{b}}$. In the case of GROMOS-C (Fig. 2) a horn antenna collects the radiation from the atmosphere and feeds it into the front end, where the signal is amplified, filtered and downconverted to a lower frequency. Afterwards the signal is spectrally analyzed by a FFT (fast Fourier transform) spectrometer. The output is linearly related to the input power. This linear relationship is determined in the calibration process.

The main parameters and specifications of GROMOS-C are summarized in Table 1 . In the following sections we describe the optics, the front end and the calibration method in detail. 


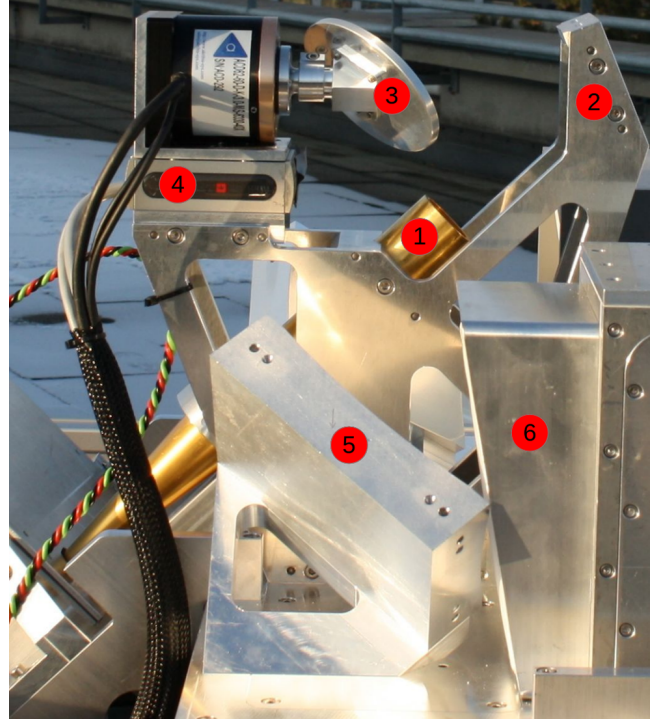

Figure 3. GROMOS-C optics (1: Horn antenna, 2: Ellipsoidal mirror, 3: Flat rotating mirror, 4: Linear translation stage 5: Ellipsoidal mirror, 6: Calibration target).

\subsection{Optics design and verification}

The optical system of GROMOS-C is shown in Fig. 3. The first optical component encountered by the incoming radiation is a flat mirror that can be rotated to select the viewing angle and scan the atmosphere in elevation from horizon to horizon. Next element is a $45^{\circ}$ off-axis ellipsoidal reflector which redirects and focuses the beam into the feed-horn.

GROMOS-C antenna is an ultra-Gaussian feed-horn (Cruickshank et al., 2007) which produces an aperture field distribution with $99.6 \%$ of the power coupling to the fundamental Gaussian beam mode. The high Gaussicity leads to reduced spillover and standing wave effects due to the significantly decreased side-lobe levels, compared to a normal corrugated feed-horn.

Two additional ellipsoidal mirrors are mounted symmetrically beside the horn and used to redirect and focus the beam into the calibration targets.

The rotating mirror is mounted on a linear translation stage that allows for the axial movement of the mirror, used for baseline cancellation. If standing waves were formed within the optics, shifting the reflector by $\lambda / 4$ and taking the mean spectra of both positions will cancel out the baselines. This axial movement of $\lambda / 4$ is applied to all measurements performed with GROMOS-C.

To be able to measure in all weather conditions, the different components of the radiometer are protected inside a sealed aluminum housing thermally insulated. A microwave window with very low losses has been built above the optics system (see Fig. 2). It has been conceived with a shape of a section of a cone, what ensures a constant incidence angle when scanning the atmosphere. The chosen material has

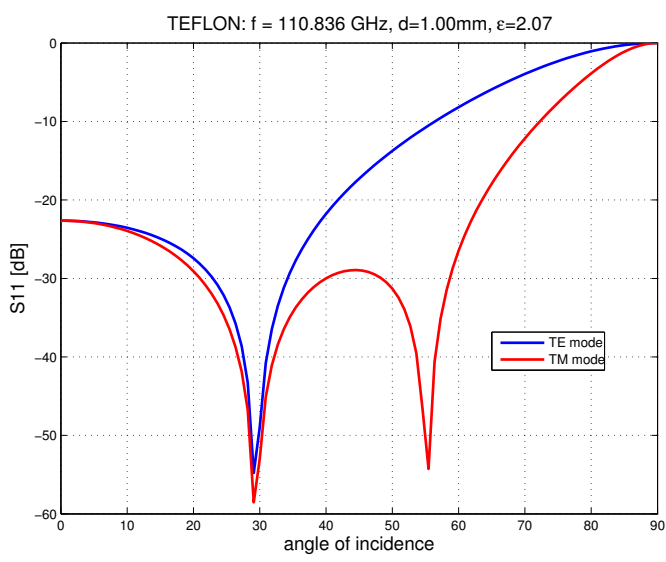

Figure 4. Reflection parameter for $1 \mathrm{~mm}$ thick teflon, simulated with Fresnel equations at the nominal frequency and for different incidence angles. The red line corresponds to the case of transversemagnetic (TM) polarization and the blue to transverse-electric polarization (TE). We observe in both cases a strong resonance at $29^{\circ}$. For the TM mode the second resonance corresponds to the Brewster angle.

been teflon because of its low losses at the frequency range of interest but also because of its stiffness and resistance to outdoor conditions. Simulations using Fresnel equations have shown that a window of teflon with a thickness of $1 \mathrm{~mm}$ and mounted at an angle of $29^{\circ}$ is the optimal configuration to minimize reflections stemming from the interfaces. Figure 4 shows the reflection parameter $\left(S_{11}=10 \log _{10} R\right.$, where $R$ is the reflectivity) for different angles of incidence. We observe in both cases a deep resonance at $29^{\circ}$ arising from the destructive interference among the reflected signals at the two interfaces.

Subsequent measurements were performed to investigate the microwave losses caused by the teflon window. It is described in detail in Fernandez et al. (2013). Measurements at horizontal incidence show a very high transmittance, 0.9988 , and this value is used to correct the sky measurements (described in Sect. 3.1). It has to be mentioned that the transmittance depends on the polarization, which varies when scanning the atmosphere. Nevertheless the variation is very small and we use a constant value for the correction.

\subsubsection{Antenna pattern}

A narrow antenna beam is required for middle atmospheric radiometric measurements, since the intensity of the received radiation depends on the path length through the atmosphere, which is determined by the elevation of the antenna beam. The narrower the antenna beam the smaller the elevation range that contributes to the received signal. Typical elevation angles for ozone observations are between 20 and $45^{\circ}$, as a compromise to optimize the middle atmosphere contribution and minimize the tropospheric attenuation. GROMOS-C optics have been designed to obtain a beam width of $5^{\circ}$. 


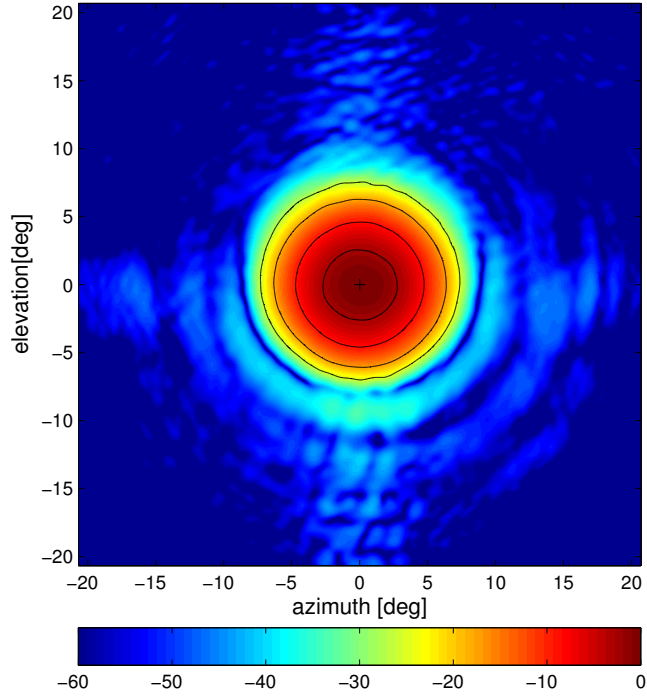

Figure 5. Farfield antenna pattern for the GROMOS-C beam pointed at horizon.

We measured the antenna pattern of GROMOS-C in the laboratory using a vector network analyzer (VNA). In order to do that we set up an open-ended waveguide probe connected to the VNA emitting a signal at $110.8 \mathrm{GHz}$ in front of GROMOS-C optics. The waveguide was mounted on a translational stage that allows for movement in the $x$ and $y$ direction. GROMOS-C horn antenna was connected to the VNA receiver, and with this configuration we measured the received radiation during a sweep of the waveguide in $x$ and $y$. Results of the antenna pattern in 1-D and 2-D are shown in Figs. 5 and 6. The antenna beam of GROMOS-C resulted to have a full width at half maximum (FWHM) of $5.15^{\circ}$, according to the expected value. Side lobes are below $-40 \mathrm{~dB}$, except for a small asymmetry in the scanning direction that can be attributed to the off-axis geometry of the ellipsoidal mirror. GRASP simulations (TICRA, 2010) show that $99.8 \%$ of the radiation hits this reflector, the remaining $0.2 \%$ may hit the frame and create the diffraction pattern observed in Fig. 5. Nevertheless this asymmetry is not critical for the measurements because it lies below the $-30 \mathrm{~dB}$ level.

\subsubsection{Instrument pointing}

The angular extent of the Sun observed from Earth is $\sim 0.5^{\circ}$, 10 times smaller than the FWHM of the antenna beam of GROMOS-C. The ephemeris of the Sun is well known; therefore it can be used to determine the elevation pointing of a radiometer by scanning a certain range around the elevation of the Sun passing through the antenna beam, assuming the Sun to be a point source. Apart from calculating the pointing offsets of GROMOS-C, the scanning of the Sun constitutes an alternative technique to obtain the antenna pattern.

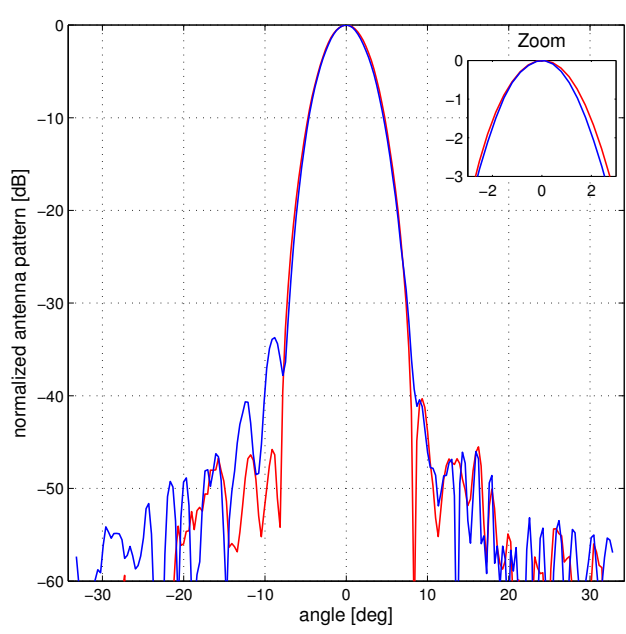

Figure 6. Planar cuts of the farfield pattern through the beam centre. The blue line corresponds to a scanning in elevation, and the red to a scanning in azimuth.
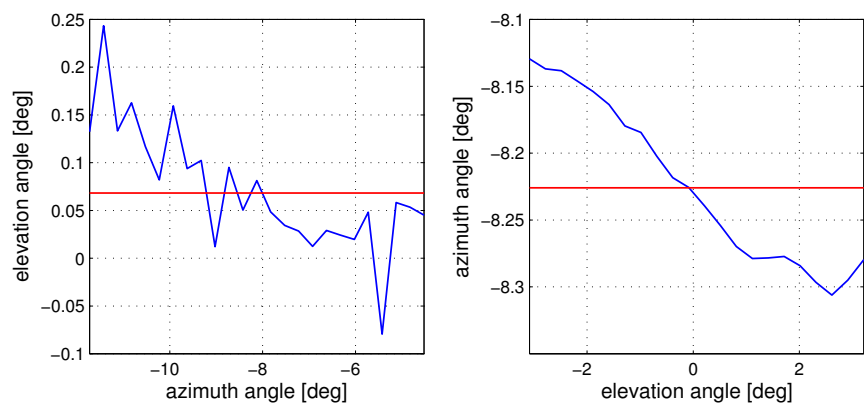

Figure 7. Pointing offsets obtained from the Sun scanning of GROMOS-C at Jungfraujoch.

We perform the scanning when the Sun is at its highest elevation, starting $1 \mathrm{~h}$ before and stopping $1 \mathrm{~h}$ after. After each scanning in elevation, a hot-cold calibration is realized. The antenna pattern obtained with this method agrees with the one measured in the laboratory, showing as well a FWHM of $5^{\circ}$. When setting up the instrument at a specific location, it is important to know the pointing offset to take into account in the data analysis. This is particularly true for campaigns. The elevation and the azimuth pointing angles of GROMOS$\mathrm{C}$ are the angles of maximum power. To calculate them precisely each sweep in elevation was fitted to a Gaussian, and the same was done for each sweep in azimuth. The difference between the maximum of the Gaussian and the Sun position maximum, calculated with the ephemerides, gives the pointing offset.

Results for the setup at Jungfraujoch are shown in Fig. 7. The slope is due to the asymmetry in the scanning direction observed in Fig. 5. The red line represents the average of the offsets in azimuth and in elevation. For Jungfraujoch we found an elevation offset of $0.07^{\circ}$ and the azimuth pointing turned out to be $8.22^{\circ}$ from south to east. 


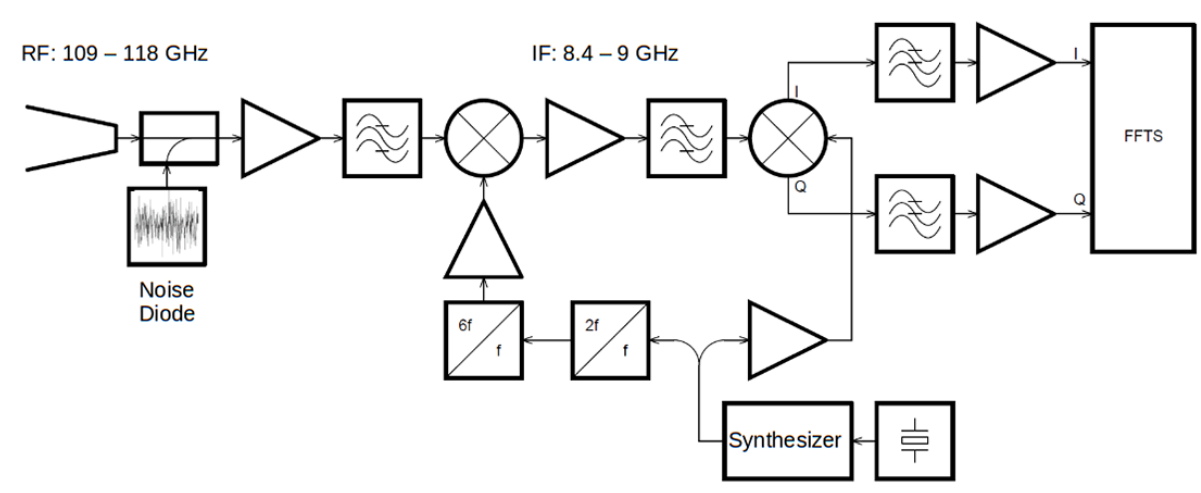

LO: $8.4-9 \mathrm{GHz}$

Figure 8. Block diagram of GROMOS-C receiver.

\subsection{Front end}

The block diagram of the GROMOS-C receiver is displayed in Fig. 8. The radiation collected by the horn is fed into the waveguide and processed by the front end. At a first step it encounters a $15 \mathrm{~dB}$ coupler which couples the signal of a noise diode, used for calibration. Then the signal is amplified by low noise amplifiers, filtered (bandpass $109-118 \mathrm{GHz}$ ) and downconverted to the intermediate frequency (IF) with a balanced mixer and a local oscillator (LO). It is therefore a single side-band heterodyne receiver. The same LO is used for a second downconversion with an IQ-mixer, which provides two baseband signals with equal power and frequency. These two signals with a bandwidth of $500 \mathrm{MHz}$ must be spectrally analyzed in order to get the spectral line information. Spectral analysis is performed with a FFT spectrometer, which consists of two parts: first an analog to digital converter samples the electric field of the incoming signal, and then the samples are directly processed by a field programmable gate array which calculates the FFT in real time. The spectrometer has a bandwidth of $1 \mathrm{GHz}$ and a resolution of $30.5 \mathrm{kHz}$.

The LO frequency can be tuned, offering the possibility to observe different emission lines: $\mathrm{O}_{3}$ at 109.559 and $110.836 \mathrm{GHz}$, and $\mathrm{CO}$ at $115.271 \mathrm{GHz}$.

The noise temperature of the receiver is currently $1080 \mathrm{~K}$. It would be significantly lower if we would remove the coupler, but we intend to use the noise diode for calibration.

The front end is thermally stabilized and insulated from the rest of the instrument to keep gain fluctuations small. Allan variance measurements revealed that gain variations start to dominate over noise level for integration times longer than $20 \mathrm{~s}$.

\subsection{Calibration}

Calibration is essential for high accuracy measurement in microwave radiometers. A way to determine the relation between the unknown brightness temperature of the sky and the output quantity of the radiometer is the commonly named hot-cold calibration, and consists of the measurement of the signal of two well defined targets, ideally blackbodies, at known temperatures:

$T_{\mathrm{b}}=\frac{T_{\mathrm{h}}-T_{\mathrm{c}}}{V_{\mathrm{h}}-V_{\mathrm{c}}} \cdot\left(V-V_{\mathrm{h}}\right)+T_{\mathrm{h}}$,

where $T_{\mathrm{h}}, T_{\mathrm{c}}$ are the temperatures of the blackbodies, $V_{\mathrm{h}}, V_{\mathrm{c}}$ the corresponding output voltages, $V$ the voltage measured by the radiometer when looking at the sky and $T_{\mathrm{b}}$ the sky brightness temperature.

The absolute accuracy depends directly on the performance of the calibration targets; thus they become a crucial part of a radiometer development and maintenance. One of GROMOS-C main features is the multiple calibration methods existent, which allows us to perform a comparison among them, to see whether they are coherent and which would be more accurate to use under different conditions.

The most accurate way to carry out the calibration using the hot-cold concept is with a cold load at a temperature close to or lower than the one measured. A simple way to reach these cryo-temperatures is to cool a piece of microwave absorber with liquid nitrogen (LN2). Yet for a campaign instrument this cannot be operated continuously and a different type of cold target has been built. We developed a new concept of cold target based on Peltier elements, which reaches $240 \mathrm{~K}$. The hot load was also designed specifically for GROMOS-C, and it is heated with resistors to $350 \mathrm{~K}$. Additionally we have a noise diode used as a super-hot load. Tipping curves (Han and Westwater, 2000) are performed by the instrument every $15 \mathrm{~min}$ in order to calculate the sky opacity. Furthermore the zenith sky can be used as a cold target. At the beginning of each campaign we perform liquid nitrogen calibrations to compare the different calibration methods.

To verify the linearity of GROMOS-C we plotted the counts of the different targets vs. their physical temperature. Results are shown in Fig. 9. The integration time was $4 \mathrm{~h}$ and 


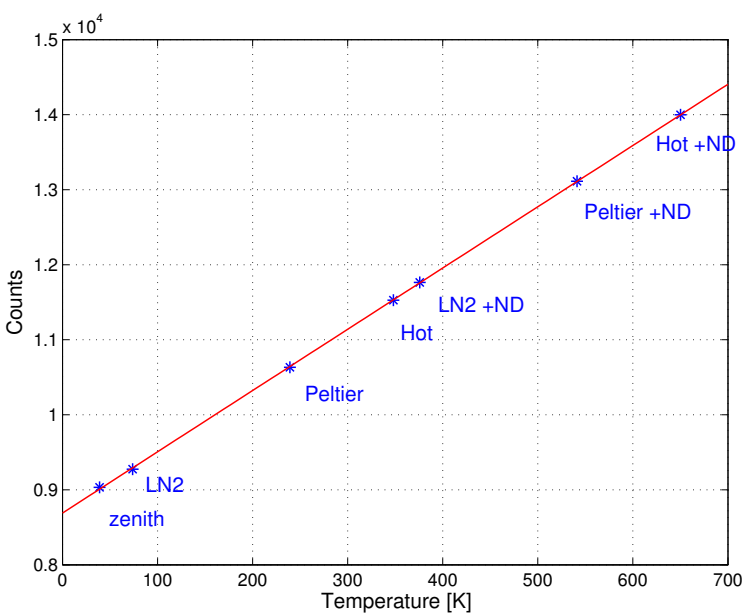

Figure 9. All the different calibration loads plotted vs. the counts measured by the spectrometer. The linear regression by least-square fit gives an $R^{2}=0.9999$.

for each target the mean of 3000 channels counts was done. In order to quantify the linearity a linear regression was performed by least-square fit. The resulted coefficient of determination, $R^{2}$, was 0.9999 which is an outstanding value.

In the next sections we explain in detail each calibration element.

\subsubsection{Calibration targets}

\section{Peltier load}

Figure 10 shows the novel design of a calibration load cooled with Peltier elements. A full description of this target is given in (Fernandez et al., 2015). The chosen geometry was a wedge cavity because the absorption is enhanced by multiple bouncing, with a half angle of $12^{\circ}$.

A metallic wedge structure was built to backup the absorber material (Eccosorb MMI-U, described in detail in Fernandez et al., 2012). The target is cooled with Peltier elements, including a system of liquid circulation to remove the heat generated on the hot surface. The liquid circulates in a closed circuit, and it is cooled in a chiller. Three Peltier elements are used to cool down the system, locating one on each of the external surfaces of the wedge and one on the baffle reflector. The system is insulated from the environment with a thick layer of Cryogel, a silica aerogel material with extremely low thermal conductivity $\left(0.039 \mathrm{~W}(\mathrm{~m} \cdot \mathrm{K})^{-1}\right)$. The microwave window is made of Plastazote (De Amici et al., 2007) and tilted by $10^{\circ}$ to avoid the formation of standing waves between the window and the mirror. This material is highly transparent at microwave frequencies, opaque for visible light and with an infrared emissivity of 0.5 . A $45^{\circ}$ mirror was included to reflect the microwave radiation from the exterior to the wedge, and absorb the infrared part. This was achieved by painting the mirror with an infrared black paint.

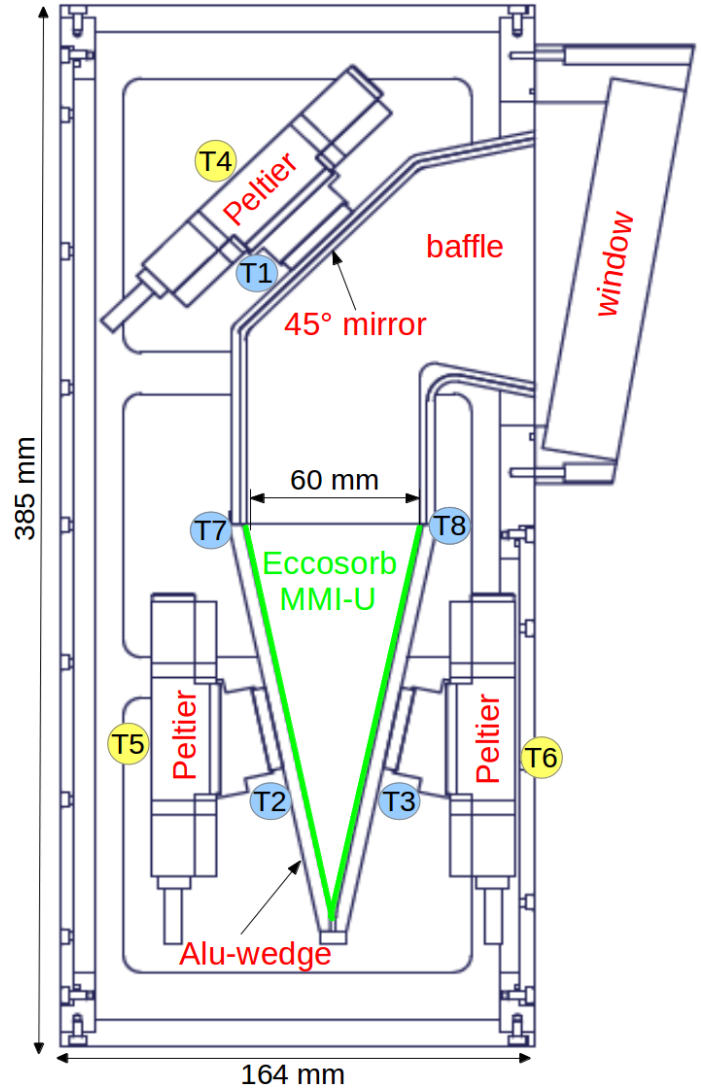

Figure 10. Schematic representation of the Peltier calibration target. The main elements are emphasized in red, the absorber material is marked in green, and the sensor positions are encircled .

The mirror is mounted on the wedge with an aluminium baffle that optimizes the insulation, and avoids the direct view of the exterior from the wedge.

Because of the low temperature reached in the inner part of the wedge $(240 \mathrm{~K})$ the frost point can be reached. In this case the presence of frost on the surface of the absorber could modify the characteristics of the blackbody. To prevent this situation the calibration load is first evacuated and then filled with nitrogen gas. The structure is airtight.

Figure 11 shows the averaged spectra of the Peltier load from the two linear positions. The data was integrated during almost $4 \mathrm{~h}$, and channels were binned to reduce the noise in the spectra. The spectra obtained in this way is quite flat over frequency, but we can still see a residual baseline with an amplitude of roughly $0.1 \mathrm{~K}$. The red line is the average temperature measured by the thermometers of the wedge. The cyan line represents the mean brightness temperature, and is very close to the mean temperature. This shows that the target has an emissivity very close to 1 , and thus is an excellent blackbody target. 


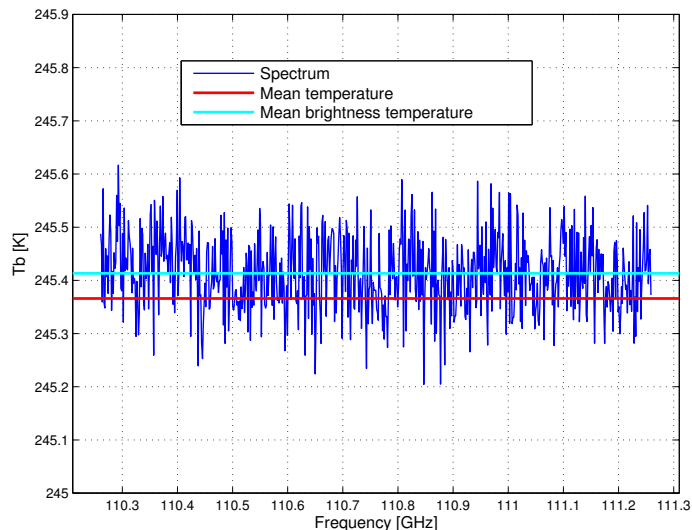

Figure 11. Peltier load brightness temperature integrated during $4 \mathrm{~h}$, calibrated with liquid nitrogen and a hot load. The red line represents the average temperature measured by the sensors on the wedge, and the cyan line is the average brightness temperature.

\section{Hot load}

GROMOS-C integrates a hot load heated with resistors up to $350 \mathrm{~K}$. The absorber material is the same as for the Peltier load (Eccosorb MMI-U) and it presents as well a similar wedge geometry. The wedge is mounted inside a box with an internal fan to keep a constant and homogeneous temperature. Several sensors monitor the temperature at different locations of the load. An average is taken for the calibration.

\section{Backscatter measurements}

In order to investigate the reflections originating in the optics of GROMOS-C from the different calibration targets, we removed the front end and connected the feed-horn directly into the vector network analyzer input. The $S_{11}$ parameter was registered over a sweep in frequency from 100 to $112 \mathrm{GHz}$. More details can be found in Fernandez et al. (2015). The reflection coefficients measured for the hot, Peltier and liquid nitrogen targets are shown in Fig. 12. At the frequency range of interest the $S_{11}$ is lower than $-65 \mathrm{~dB}$ for both Peltier and hot loads, which constitutes a very acceptable value of low reflectivity.

For the liquid nitrogen the incidence angle was perpendicular, and the resulting $S_{11}$ parameter is quite high, higher than $-25 \mathrm{~dB}$ at the frequency of interest. The backscatter originates mainly at the air-nitrogen interface due to the reflectivity of the surface of almost 1\% (Maschwitz et al., 2013). We have verified that looking at the liquid nitrogen at an angle different than orthogonal reduces considerably the level of reflections.

This results justifies the use of the Peltier load over the traditional liquid nitrogen target: even if we can not reach cryogenic temperatures the induced error is compensated by a much lower reflection level.

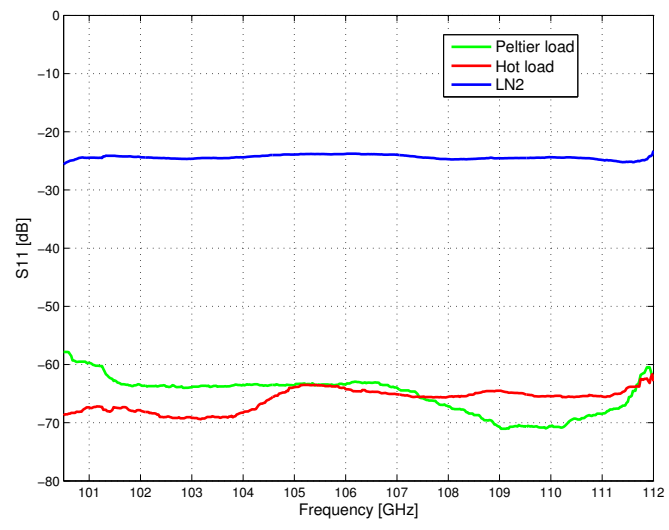

Figure 12. $S_{11}$ measured for the Peltier, hot and liquid nitrogen targets with the vector network analyzer for the frequency interval 100-112 GHz.

\subsubsection{Noise diode}

Additionally a noise diode can be used as a super-hot target to calibrate GROMOS-C (super hot in this context means a temperature well above any physical temperature of the atmosphere). The noise is injected into the receiver before the RF amplification with a $15 \mathrm{~dB}$ coupler, that couples the signal with the radiation collected by the antenna. The additional brightness temperature sensed by the detector when the noise diode is on is called noise diode temperature $\left(T_{\text {nd }}\right)$. The noise diode is calibrated periodically with hot and cold loads (LN2 calibrations sporadically), and its temperature is calculated with

$T_{\mathrm{nd}}=\frac{T_{\mathrm{h}}-T_{\mathrm{c}}}{V_{\mathrm{h}}-V_{\mathrm{c}}} \cdot\left(V_{\mathrm{hnd}}-V_{\mathrm{h}}\right)$,

where $T_{\mathrm{h}}, T_{\mathrm{c}}$ are the temperatures of both loads, $V_{\mathrm{h}}, V_{\mathrm{c}}$ the output voltages, and $V_{\text {hnd }}$ the voltage measured by the radiometer when looking at the hot load with the noise diode on.

The spectrum of GROMOS-C noise diode obtained this way is shown in Fig. 13. It presents a strong frequency dependance. The different colours correspond to the calibration of the noise diode while the mirror is pointing at the three different loads. The fact that the sensed noise is equivalent (differences smaller than $0.5 \%$ ) corroborates the linearity of the receiver. The spectra is stable on time as long as the front end temperature is kept constant. We have observed that the noise is very sensitive to temperature fluctuations; therefore this calibration method is not ideal for unstable conditions, otherwise the diode should be recalibrated very frequently.

The atmospheric brightness temperature calibrated using the noise diode is obtained with the following equation:

$T_{\mathrm{b}}=\frac{V}{G}-T_{\mathrm{r}}$, 


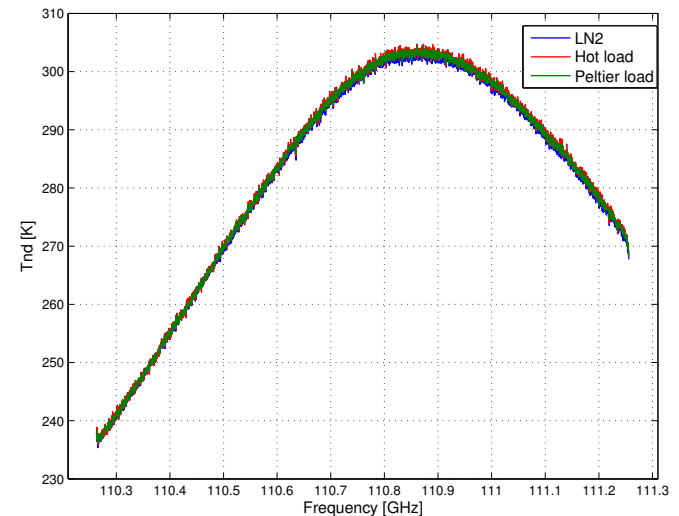

Figure 13. Noise diode temperature calibrated with the Peltier, hot and liquid nitrogen targets.

where the gain $(G)$ and the receiver temperature $\left(T_{\mathrm{r}}\right)$ are given by

$T_{\mathrm{r}}=\frac{T_{\mathrm{h}}\left(T_{\mathrm{h}}+T_{\mathrm{nd}}\right)-V_{\mathrm{hnd}} T_{\mathrm{h}}}{V_{\mathrm{hnd}}-V_{\mathrm{h}}}$,

$G=\frac{V_{\mathrm{hnd}}-V_{\mathrm{h}}}{T_{\mathrm{nd}}}$.

\subsubsection{Tipping curve}

Another conventional method to realize a cold reference is by means of a tipping curve (Han and Westwater, 2000), which consists of measurements of the brightness temperature of the sky under different elevation angles. From these measurements it is possible to determine the zenith opacity, and therefore the sky temperature so that the sky itself can be used as a cold target. Assuming a one-layered atmosphere with mean temperature $T_{\mathrm{m}}$, the brightness temperature sensed at each angle $\theta$ will be

$T_{\mathrm{b}}(\theta)=T_{\mathrm{b} 0} \cdot e^{-\tau(\theta)}+\left(1-e^{-\tau(\theta)}\right) \cdot T_{\mathrm{m}}$,

where $T_{\mathrm{b} 0}$ the microwave background temperature $(2.7 \mathrm{~K})$ and $\tau$ the opacity. We can solve for $\tau$ and find the zenith opacity by an iterative process.

This requires a horizontally stratified atmosphere, and hence this type of calibration is only reliable under clear-sky conditions. This approach requires an estimation of the sky mean temperature, which we obtain from the ground temperature according to Ingold (Ingold et al., 1998):

$T_{\mathrm{m}}=T_{\text {ground }}+\Delta T$,

where $\Delta T$ depends on the frequency range and on the location (mainly the altitude), being for Jungfraujoch $-16 \mathrm{~K}$ at $110 \mathrm{GHz}$.

The problem related to the presence of clouds in the sky gets worse for shorter wavelengths because the absorption coefficient of atmospheric liquid water increases with frequency. Yet GROMOS-C has the other loads available which are more reliable under cloudy conditions.

\section{Data processing and results}

The operational cycle of GROMOS-C works as follows: measurements are taken at sky $30^{\circ}$ elevation north at two linear positions separated $\lambda / 4$, and the same is done for zenith and $30^{\circ}$ elevation south. Then the optics point to the hot and Peltier loads, and at each load a measurement with the noise diode on and off is taken, again at two linear positions. That makes a total of 14 measurements per cycle, with $1 \mathrm{~s}$ integration time at each position. A tipping curve is performed every $15 \mathrm{~min}$. On average a calibration cycle takes $15 \mathrm{~s}$, of which approximately $43 \%$ is dedicated to the line measurement.

Before feeding the spectra to the inversion model a preprocessing is performed in order to correct the data for the attenuation originating from the microwave window and the tropospheric absorption.

\section{Window correction}

The incident radiation at the air-window interface will be either transmitted, absorbed or reflected. The measured brightness temperature can be expressed as follows:

$T_{\mathrm{bw}}=t \cdot T_{\mathrm{b}}+a \cdot T_{\mathrm{w}}+r \cdot T_{\mathrm{env}}$

where $T_{\mathrm{b}}$ is the brightness temperature measured without window, $T_{\mathrm{bw}}$ with window, $T_{\mathrm{w}}$ the physical temperature of the window and $T_{\text {env }}$ the temperature of the environment inside the instrument. Assuming $T_{\mathrm{env}} \simeq T_{\mathrm{w}}$, and given that $t+a+r=1$, we can express

$T_{\mathrm{bw}}=t \cdot T_{\mathrm{b}}+(1-t) \cdot T_{\mathrm{w}}$.

We performed measurements in the laboratory of the brightness temperature of a LN2 target with and without window, keeping the temperature constant. The temperature of the window is monitored with a sensor inside of the instrument. Solving for the transmittance we have obtained $t=0.9988$.

Based on this result we apply Eq. (12) to correct every atmospheric spectrum.

\section{Tropospheric correction}

The contribution of the tropospheric emission to the measured brightness temperature is substantial and it can significantly vary depending on the atmospheric conditions. Water vapour inhomogeneities in the troposphere are difficult to model; therefore it is important to correct the measured spectra for the tropospheric effect, and locate the lower boundary of the retrieval at the tropopause level. 


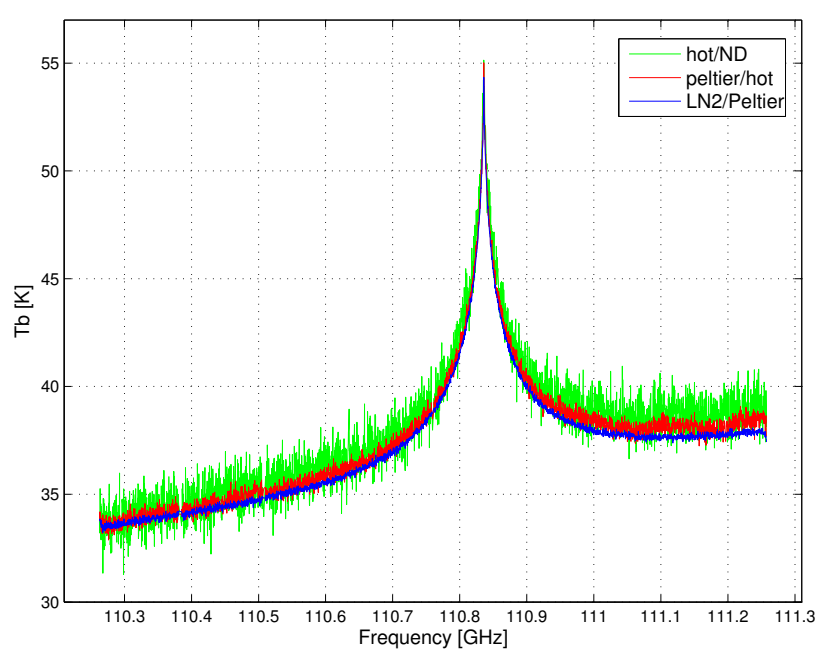

Figure 14. Ozone measured spectra calibrated with different combinations of cold and hot loads.

According to Eq. (9), the brightness temperature that the radiometer would measure at the tropopause level, $T_{\mathrm{b}}\left(z_{\text {trop }}\right)$, would be

$T_{\mathrm{b}}\left(z_{\text {trop }}\right)=\frac{T_{\mathrm{b}}\left(z_{0}\right)-T_{\text {trop }} \cdot\left(1-e^{-\tau}\right)}{e^{-\tau}}$,

being $T_{\mathrm{b}}\left(z_{0}\right)$ the brightness temperature measured at the surface and $T_{\text {trop }}$ the mean temperature of the troposphere, calculated with Eq. (10). The tropospheric opacity can be calculated with different methods; in our case we opted for considering only the wings of the measured spectra, which correspond to the continuum emission due to tropospheric oxygen and water vapour. Neglecting the ozone emission, the radiation registered at the tropopause level would be only the cosmic background. Solving Eq. (13) for $\tau$, the zenith opacity is calculated with

$\tau=-\ln \left(\frac{T_{\text {trop }}-T_{\mathrm{b}}\left(z_{0}\right)}{T_{\text {trop }}-T_{\mathrm{bg}}}\right)$.

In Fig. 14 we show an ozone spectrum calibrated using different combinations of calibration loads. The measurement was performed the 20 February at Jungfraujoch. The integration time was $4 \mathrm{~h}$ and binning is performed every 10 channels, resulting in a resolution of $300 \mathrm{kHz}$. To calculate the liquid nitrogen temperature we read the pressure from the meteorological station and applied Clausius-Clapeyron equation. The noise diode was calibrated the same day, during 1:30 h. It is noticeable that the noise level is higher for the ozone spectrum calibrated with the noise diode. This is expected because the noise diode spectrum itself is noisier than the spectrum of the other calibration targets, and because the errors are amplified by the extrapolation towards the colder atmosphere.

Differences between the spectra are shown in Fig. 15 . Looking closely at the difference between the calibrated
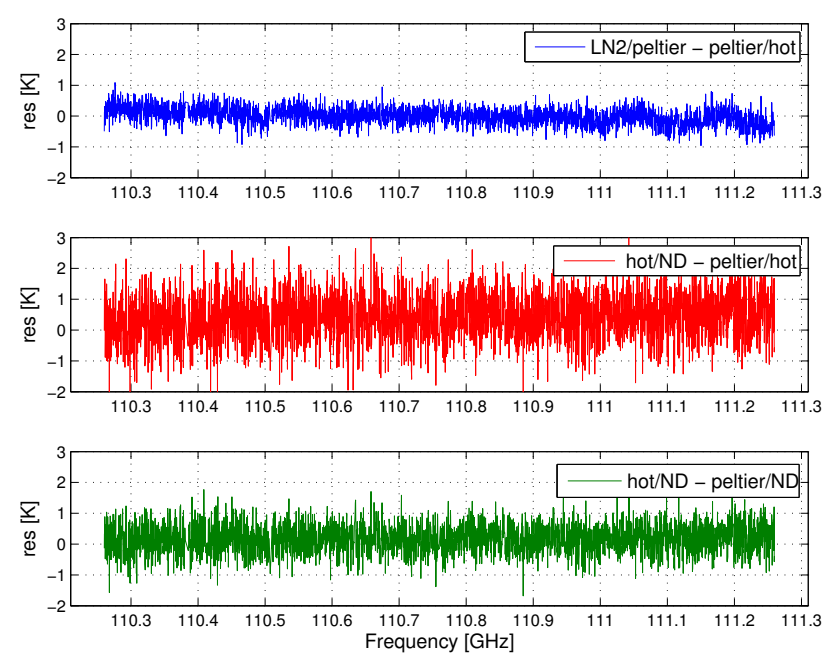

Figure 15. Residuals, corresponding to differences between the spectra calibrated with different loads in Fig. 14. The first always indicates the corresponding load used as cold load whereas the second indicates the hot load. Note the hot load can be used as a cold load and vice versa.

spectra with and without LN2 (blue line) one can perceive a frequency dependence of the offset. It could be due to a window effect produced by a frequency dependent reflection coefficient, while we are considering a constant value for the correction within the whole bandwidth.

\subsection{Retrieval implementation}

The vertical distribution of ozone is calculated from the observed emission spectrum through an inversion process. For the ozone profiles retrievals of GROMOS-C, the Atmospheric Radiative Transfer Simulator ARTS2 (Eriksson et al., 2011) is used as the forward model. It simulates atmospheric radiative transfer and calculates the spectral intensity of the pressure broadened ozone emission line of interest for a model atmosphere using an a priori ozone profile. The associated Matlab package Qpack2 (Eriksson et al., 2005) makes use of ARTS2 by comparing the ozone modelled spectrum with the one measured by GROMOS-C. The best estimate of the vertical profile of ozone volume mixing ratio is done by means of the optimal estimation method (OEM) (Rodgers, 1976), considering uncertainties in the measured ozone spectrum and in the a priori profile.

In the standard retrieval of GROMOS-C, the spectrometer channels are not binned using the whole frequency resolution of $30.5 \mathrm{kHz}$. Averaging of spectra is performed by integration in time, using typically a time resolution of $30 \mathrm{~min}$. Ozone profiles can be retrieved from the resulted averaged spectra, yielding to a reliable profile of ozone from approximately $23-70 \mathrm{~km}$ with a vertical resolution of around $10-12 \mathrm{~km}$ in the stratosphere, which increases with altitude to $20 \mathrm{~km}$ in 

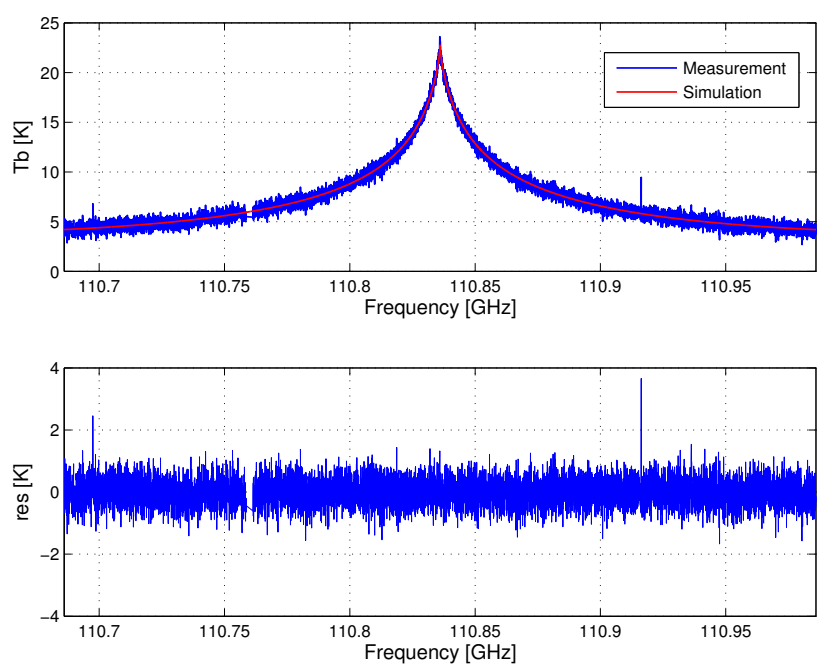

Figure 16. Above, measured and simulated 1-day ozone spectrum; below, residuals between simulation and measurement.

the mesosphere, corresponding to the width of the averaging kernels (see below).

\section{Validation campaign on Jungfraujoch}

The Sphinx Observatory is located at Jungfraujoch, at $3580 \mathrm{~m}$ a.s.l, and belongs to the High Altitude Research Stations. GROMOS-C was installed in the terrace of Sphinx in mid-January 2014, and transported back to Bern at the end of March 2014.

The goal of this first measurement campaign was to evaluate the performance of the instrument under extreme weather conditions, as well as to collect high-resolution ozone spectra at high altitude, retrieve vertical profiles and validate the instrument by comparing with ozone profiles from other sources.

At high altitudes the atmosphere is very dry, hence the tropospheric opacity is very low. Therefore the measured spectra is less attenuated, and the line amplitude is larger than those measured at low altitudes. During the campaign, the weather was mainly cold with minimum temperatures of $-23^{\circ} \mathrm{C}$ and maximum close to $0{ }^{\circ} \mathrm{C}$. Wind has often been very strong, affecting the thermal regulation of GROMOS$\mathrm{C}$ housing. Additional heaters where installed to solve this problem, but still the very cold and windy days the thermal stability was not as good as expected, affecting the stability of the noise diode. However this does not pose a problem as different calibration schemas are still feasible.

The presence of snow on the microwave window modifies its opacity. This was observed as higher brightness temperatures measured at zenith than at lower elevations during snowfalls. A system of warm air blown onto the surface of the window was designed to solve the snow problem by preventing its deposition on the surface.
Atmospheric opacity was calculated periodically with the tipping curves, and resulted to be between 0.05 and 0.1 under good weather conditions.

The top plot of Fig. 16 shows a typical 1-day ozone spectrum after applying the tropospheric correction. The red line corresponds to the calculated spectrum by the forward model based on the retrieved ozone profile. The bottom plot shows the residuals between the measured and the estimated spectrum. Notice the absence of baseline features.

Figure 17 shows an ozone profile retrieved from a 1-day spectrum with $300 \mathrm{MHz}$ bandwidth around the line centre. The chosen date corresponds to a typical day with very low opacity. For the retrieval, a temperature-altitude-pressure profile is required, that we take from the ECMWF model for the given location and time, interpolating the pressure to the precise altitude. For the a priori profile, we use a climatology from MLS (Microwave Limb Sounding on the Aura satellite) data 2004-2013, monthly mean. The covariance matrix of the measurement is obtained by first computing the noise level of the measurement, considered constant for all channels. The matrix is built as a diagonal matrix where the elements in the diagonal are the square of the noise, and the other elements are set to zero. The covariance matrix of the a priori profile is built by considering a Gaussian correlation decay at neighbouring layers with a maximum value at the diagonal of $0.4 \mathrm{ppm}$. Spectroscopic data about the absorption species is needed for ARTS to calculate the absorption coefficient for the radiative transfer. For water and oxygen, the continuum and the peaks are simulated with the Rosenkranz model (Rosenkranz, 1998). The water vapour profile is taken from ECMWF, interpolated to the pressure grid. Oxygen and nitrogen profiles are taken as constant profiles. The spectroscopic parameters for the ozone line are taken from the JPL (Jet Propulsion Laboratory) catalog merged with the broadening parameters from the HITRAN catalog.

The error bars included in the left panel of Fig. 17 represent the total retrieval error, that is, the standard deviation for the sum of the observation and smoothing error.

A comparison of the GROMOS-C-retrieved profile with the MLS and ECMWF profiles is shown in the middle plots of Fig. 17, as well as the profiles obtained from GROMOS, the brother NDACC instrument of GROMOS-C in Bern (60 km from Jungfraujoch). MLS profiles present a higher vertical resolution than GROMOS-C retrievals; we therefore have to convolve the MLS profiles with the averaging kernels of our inversions (Tschanz et al., 2013) according to Eq. (15):

$x_{\mathrm{MLS}, \mathrm{conv}}=A \cdot\left(x_{\mathrm{MLS}}-x_{a}\right)+x_{a}$,

where $A$ is the averaging kernel matrix, $x$ stands for $O_{3}$ profile, with $x_{\mathrm{a}}$ being the a priori profile of our retrievals. The convolution decreases the vertical resolution of the satellite profiles and allows for an adequate comparison. 

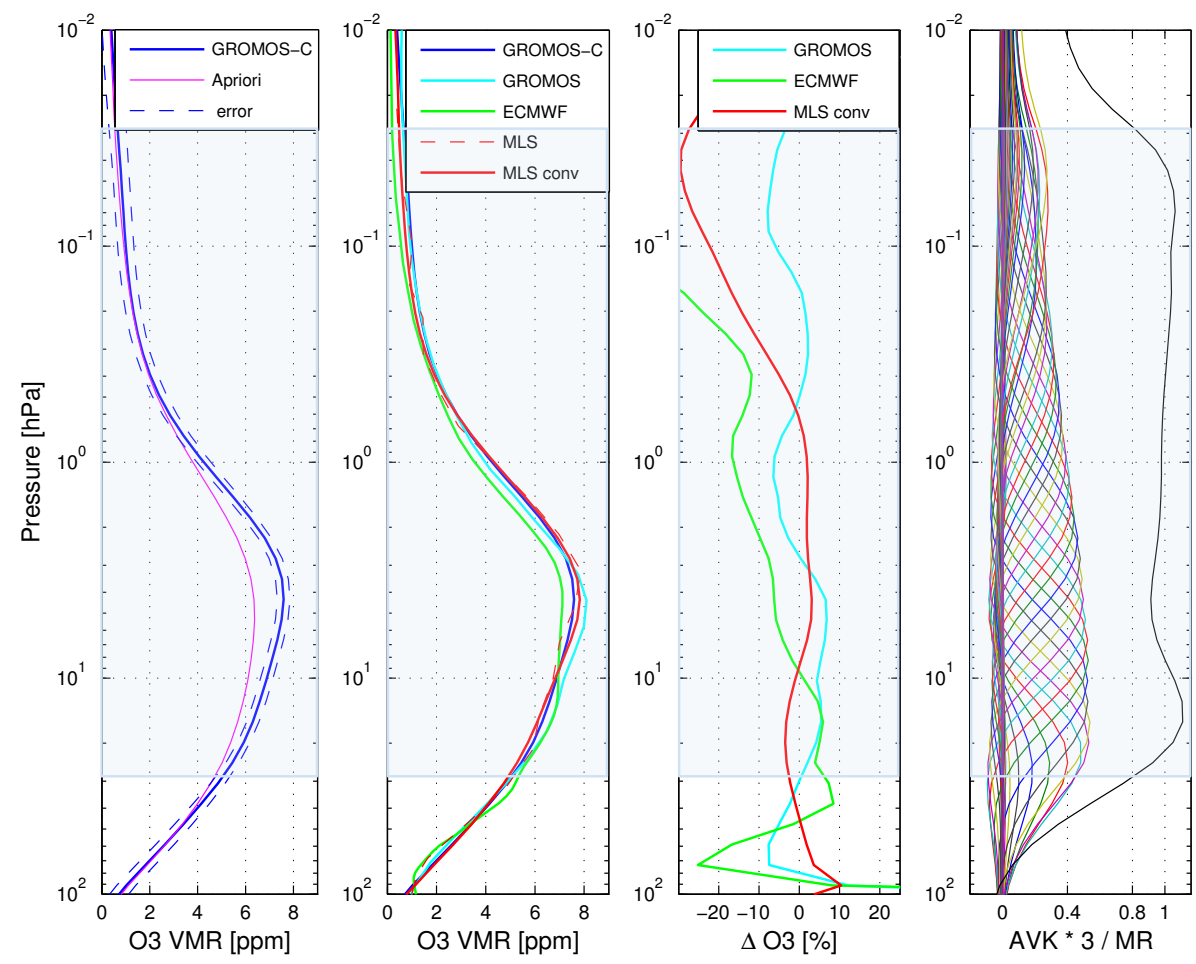

Figure 17. Example of an ozone vertical profile retrieved from a daily mean spectrum (21 January 2014), plotted together with the a priori profile and the total error limits. A comparison of the profile with MLS, GROMOS and ECMWF is shown in the middle plots. The averaging kernels and the measurement response are shown on the right side plot. The shadow covers the altitudes where the measurement response is bigger than 0.8 .

The mean relative difference profile was calculated in percent and with respect to GROMOS-C as follows:

$\Delta \mathrm{O}_{3}=\frac{\mathrm{O}_{3 \text { (compared) }}-\mathrm{O}_{3 \text { (retrieved) }}}{\mathrm{O}_{3 \text { (retrieved) }}} \cdot 100$.

Results show an agreement with the radiometer in Bern within the $10 \%$ at all levels. Comparing with MLS the profiles agree up to the lower mesosphere, from where our retrieval seems to overestimate the volume mixing ratio of ozone. The overestimation gets more pronounced when we compare with the model. Nevertheless in the mesosphere the ozone concentration becomes so low that a small discrepancy affects the relative difference in a significant way.

The averaging kernels and the measurement response are shown on the right side plot of Fig. 17. The shaded area covers the altitudes where the measurement response is larger than 0.8. We can conclude that for GROMOS-C, ozone volume mixing ratio profiles are retrieved with less than $20 \%$ a priori contribution from 30 to $0.03 \mathrm{hPa}$, which corresponds to altitudes between 23 and $70 \mathrm{~km}$.

The retrievals were run each day, with 30 minutes integration time, from the 15 January to the 4 March. Figure 18 shows the mean volume mixing ratio of ozone for three selected pressure levels and its evolution on time compared to the correspondent MLS and GROMOS values.
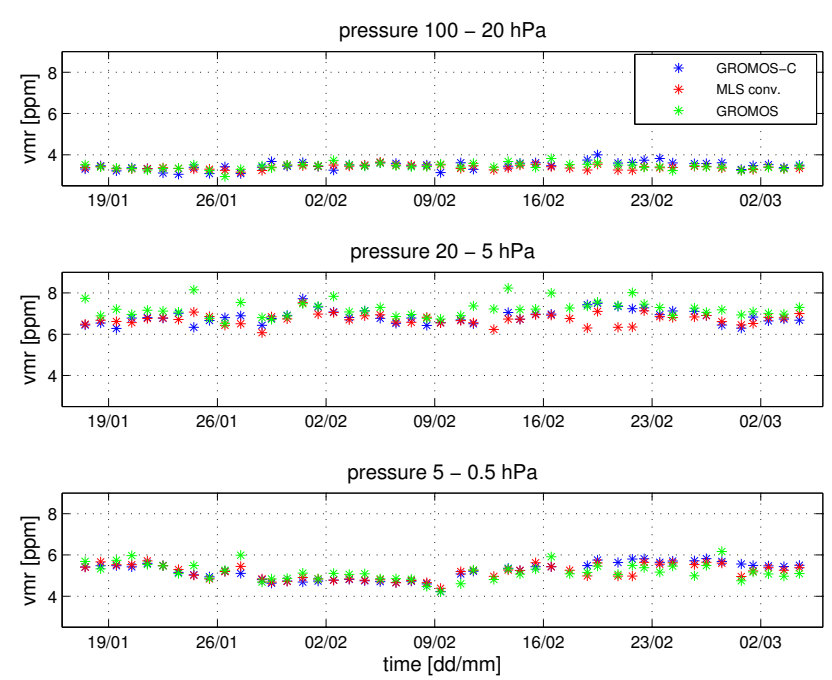

Figure 18. Time series of ozone volume mixing ratio for three pressure levels, retrieved by GROMOS-C and compared with MLS convolved, during the Jungfraujoch campaign. 


\section{Conclusions}

GROMOS-C is a new ground-based radiometer for middle atmospheric ozone designed for measurement campaigns. It combines a preamplified heterodyne receiver and an FFT spectrometer with a sophisticated optical system. Its compact design and remote control makes it suitable for campaign use, even at remote places.

The different parts of the instrument have been thoroughly designed and characterized. The antenna beam of GROMOS$\mathrm{C}$ presents a half power beam width of $5^{\circ}$. The receiver has been optimized to reduce the receiver noise temperature, which is currently $1080 \mathrm{~K}$. The changeable LO frequency allows the possibility to observe different emission lines, including two $\mathrm{O}_{3}$ and one $\mathrm{CO}$ line.

Calibration is performed with the hot-cold concept, using a new type of calibration load specifically designed for this instrument. The calibration scheme does not depend on the use of liquid nitrogen. The additional calibration methods, noise diode and tipping curve agree, leading to very similar spectra. The big advantage of having several calibration modes lies on the possibility to choose the optimal for each situation. For example, when the troposphere is rather cloudy the tipping curve would be less accurate. Under unstable conditions the noise diode is not ideal as its emission depends on temperature. The Peltier and hot loads are better thermally stabilized and not weather dependent. However, they span a temperature range much smaller than when using the sky as cold load or the diode as hot load.

The validation campaign at Jungfraujoch proved that GROMOS-C can provide ozone profiles in the middle atmosphere, specifically between 23 and $70 \mathrm{~km}$.

Comparisons show a very good overall agreement with the NDACC radiometer GROMOS, as well as with MLS profiles, being in more discrepancy with the model ECMWF. The accordance between the retrievals of GROMOS and GROMOS-C is within $10 \%$ at all levels, and with MLS for pressure altitudes between 30 and $0.3 \mathrm{hPa}$.

The measurement response for the single day retrievals of GROMOS-C is higher than $80 \%$ for pressure levels between 30 and $0.03 \mathrm{hPa}$. The averaging kernels peak at the right level for the stratosphere but not in the upper mesosphere, where discrepancies with MLS and ECMWF arise.

The time evolution in daily mean ozone concentration is similar for the measurements of MLS, GROMOS and the radiometer under test, at the plotted levels, except for a few days in February with strong snowfall.

We have currently added a second spectrometer to GROMOS-C, which presents a very high spectral resolution $\left(3 \mathrm{KHz}\right.$ channel $\left.^{-1}\right)$. An additional external mirror has also been installed which allows for four-directional observations. These two new updates have been implemented with the purpose of measuring wind profiles, based on Doppler shift, according to the concept of Rüfenacht et al. (2012). This will be tested in the next campaign in La Reunion island, located in the Indian ocean.

Acknowledgements. This work has been funded by the Swiss National Science Foundation under grant number 200020-146388. The authors want to thank the HFSJ observatory for their hospitality and support during the campaign. Special thanks go to the electronics and mechanics workshops of the IAP, and to Mark Whale for helping in the design of the optics.

Edited by: D. Feist

\section{References}

Boyd, I. S., Parrish, A. D., Froidevaux, L., Von Clarmann, T., Kyrölä, E., Russell, J. M., and Zawodny, J. M.: Ground-based microwave ozone radiometer measurements compared with AuraMLS v2. 2 and other instruments at two network for detection of atmospheric composition change sites, J. Geophys. Res.-Atmos., 112, D24S33, doi:10.1029/2007JD008720, 2007.

Butchart, N., Scaife, A. A., Bourqui, M., de Grandpré, J., Hare, S. H. E., Kettleborough, J., Langematz, U., Manzini, E., Sassi, F., and Shibata, K.; Shindell, D., and Sigmond, M.: Simulations of anthropogenic change in the strength of the Brewer-Dobson circulation, Clim. Dynam., 27, 727-741, 2006.

Cruickshank, P. A. S., Bolton, D. R., Robertson, D. A., Wylde, R. J., and Smith, G. M.: Reducing standing waves in quasi-optical systems by optimal feedhorn design, IEEE, 44, 941-942, doi:10.1109/ICIMW.2007.4516802, 2007.

Dall'Amico, M., Gray, L. J., Rosenlof, K. H., Scaife, A. A., Shine, K. P., and Stott, P. A.: Stratospheric temperature trends: impact of ozone variability and the QBO, Clim. Dynam., 34, 381-398, 2010.

De Amici, G., Layton, R., Brown, S. T., and Kunkee, D.: Stabilization of the brightness temperature of a calibration warm load for spaceborne microwave radiometers, IEEE T. Geosci. Remote, 45, 1921-1927, 2007.

Eriksson, P., Jiménez, C., and Buehler, S. A.: Qpack, a general tool for instrument simulation and retrieval work, J. Quant. Spectrosc. Ra., 91, 47-64, 2005.

Eriksson, P., Buehler, S., Davis, C., Emde, C., and Lemke, O.: ARTS, the atmospheric radiative transfer simulator, version 2, J. Quant. Spectrosc. Ra., 112, 1551-1558, 2011.

Farman, J., Murgatroyd, R., Silnickas, A., and Thrush, B.: Ozone photochemistry in the Antarctic stratosphere in summer, Q. J Roy. Meteor. Soc., 111, 1013-1025, 1985.

Fernandez, S., Murk, A., and Kämpfer, N.: Characterization of microwave cavity resonance absorbers from Emerson and Cuming, Tech. rep., IAP, Bern, available at: http://www.iap.unibe.ch/ publications/, last access date: July, 2012.

Fernandez, S., Murk, A., and Kämpfer, N.: Characterization of GROMOS-C optics, Tech. rep., IAP, Bern, available at: http: //www.iap.unibe.ch/publications/ (last access date: December 2013), 2013.

Fernandez, S., Murk, A., and Kampfer, N.: Design and characterization of a Peltier-cold calibration target for a $110-\mathrm{GHz}$ radiometer, IEEE T. Geosci. Remote, 53, 344-351, 2015. 
Flury, T., Hocke, K., Haefele, A., Kämpfer, N., and Lehmann, R.: Ozone depletion, water vapor increase, and PSC generation at midlatitudes by the 2008 major stratospheric warming, J. Geophys. Res.-Atmos., 114, D18302, doi:10.1029/2009JD011940, 2009.

Godin-Beekmann, S. and Nair, P. J.: Sensitivity of stratospheric ozone lidar measurements to a change in ozone absorption crosssections, J. Quant. Spectrosc. Ra., 113, 1317-1321, 2012.

Han, Y. and Westwater, E. R.: Analysis and improvement of tipping calibration for ground-based microwave radiometers, IEEE T. Geosci. Remote, 38, 1260-1276, 2000.

Hocke, K., Kämpfer, N., Ruffieux, D., Froidevaux, L., Parrish, A., Boyd, I., von Clarmann, T., Steck, T., Timofeyev, Y. M., Polyakov, A. V., and Kyrölä, E.: Comparison and synergy of stratospheric ozone measurements by satellite limb sounders and the ground-based microwave radiometer SOMORA, Atmos. Chem. Phys., 7, 4117-4131, doi:10.5194/acp-7-4117-2007, 2007.

Ingold, T., Peter, R., and Kämpfer, N.: Weighted mean tropospheric temperature and transmittance determination at millimeter-wave frequencies for ground-based applications, Radio Sci., 33, 905918, 1998.

Kaempfer, N. A.: Microwave remote sensing of the atmosphere in Switzerland, Opt. Eng., 34, 2413-2424, 1995.

Lobsiger, E., Künzi, K., and Dütsch, H.: Comparison of stratospheric ozone profiles retrieved from microwave-radiometer and Dobson-spectrometer data, J. Atmos. Terr. Phys., 46, 799-806, 1984.

Maillard Barras, E., Ruffieux, D., and Hocke, K.: Stratospheric ozone profiles over Switzerland measured by SOMORA, ozonesonde and MLS/AURA satellite, Int. J. Remote Sens., 30, 4033-4041, 2009.

Manney, G. L., Santee, M. L., Rex, M., Livesey, N. J., Pitts, M. C., Veefkind, P., Nash, E. R., Wohltmann, I., Lehmann, R., Froidevaux, L., Poole, L. R., Schoeberl, M. R., Haffner, D. P., Davies, J., Dorokhov, V., Gernandt, H., Johnson, B., Kivi, R., Kyrö, E., Larsen, N., Levelt, P. F., Makshtas, A., McElroy, C. T., Nakajima, H., Parrondo, M. C., Tarasick, D. W., von der Gathen, P., Walker, K. A., and Zinoviev, N. S.: Unprecedented Arctic ozone loss in 2011, Nature, 478, 469-475, 2011.

Maschwitz, G., Löhnert, U., Crewell, S., Rose, T., and Turner, D. D.: Investigation of ground-based microwave radiometer calibration techniques at $530 \mathrm{hPa}$, Atmos. Meas. Tech., 6, 2641-2658, doi:10.5194/amt-6-2641-2013, 2013.

Nagahama, T., Nakane, H., Fujinuma, Y., Morihira, A., Mizuno, A., Ogawa, H., and Fukui, Y.: Ground-based millimeter-wave radiometer for measuring the stratospheric ozone over Rikubetsu, Japan, J. Meteorol. Soc. Jpn., 85, 495-509, 2007.
Palm, M., Hoffmann, C. G., Golchert, S. H. W., and Notholt, J.: The ground-based MW radiometer OZORAM on Spitsbergen - description and status of stratospheric and mesospheric $\mathrm{O}_{3}$-measurements, Atmos. Meas. Tech., 3, 1533-1545, doi:10.5194/amt-3-1533-2010, 2010.

Penfield, H., Litvak, M., Gottlieb, C., and Lilley, A.: Mesospheric ozone measured from ground-based millimeter wave observations, J. Geophys. Res., 81, 6115-6120, 1976.

Rodgers, C. D.: Retrieval of atmospheric temperature and composition from remote measurements of thermal radiation, Rev. Geophys., 14, 609-624, 1976.

Rosenkranz, P. W.: Water vapor microwave continuum absorption: a comparison of measurements and models, Radio Sci., 33, 919928, 1998.

Rüfenacht, R., Kämpfer, N., and Murk, A.: First middleatmospheric zonal wind profile measurements with a new ground-based microwave Doppler-spectro-radiometer, Atmos. Meas. Tech., 5, 2647-2659, doi:10.5194/amt-5-2647-2012, 2012.

Steinbrecht, W., Claude, H., Schönenborn, F., McDermid, I. S., Leblanc, T., Godin-Beekmann, S., Keckhut, P., Hauchecorne, A., Van Gijsel, J. A. E., Swart, D. P. J., Bodeker, G. E., Parrish, A., Boyd, I. S., Kämpfer, N., Hocke, K., Stolarski, R. S., Frith, S. M., Thomason, L. W., Remsberg, E. E., Von Savigny, C., Rozanov, A., and Burrows, J. P.: Ozone and temperature trends in the upper stratosphere at five stations of the Network for the Detection of Atmospheric Composition Change, Int. J. Remote Sens., 30, 3875-3886, 2009.

Straub, C., Murk, A., and Kämpfer, N.: MIAWARA-C, a new ground based water vapor radiometer for measurement campaigns, Atmos. Meas. Tech., 3, 1271-1285, doi:10.5194/amt-31271-2010, 2010.

Studer, S., Hocke, K., Pastel, M., Godin-Beekmann, S., and Kämpfer, N.: Intercomparison of stratospheric ozone profiles for the assessment of the upgraded GROMOS radiometer at Bern, Atmos. Meas. Tech. Discuss., 6, 6097-6146, doi:10.5194/amtd6-6097-2013, 2013.

TICRA: GRASP9 - Technical Description, Tech. rep., TICRA, Copenhagen, Denmark, 2010.

Tschanz, B., Straub, C., Scheiben, D., Walker, K. A., Stiller, G. P., and Kämpfer, N.: Validation of middle-atmospheric campaignbased water vapour measured by the ground-based microwave radiometer MIAWARA-C, Atmos. Meas. Tech., 6, 1725-1745, doi:10.5194/amt-6-1725-2013, 2013.

Zommerfelds, W., Kunzi, K., Summers, M., Bevilacqua, R., Strobel, D., Allen, M., and Sawchuck, W.: Diurnal variations of mesospheric ozone obtained by ground-based microwave radiometry, J. Geophys. Res.-Atmos., 94, 12819-12832, 1989. 